\title{
Comparative development of knowledge-based bioeconomy in the European Union and Turkey
}

\author{
Didem Celikkanat Ozan ${ }^{1}$ and Yusuf Baran ${ }^{2}$ \\ ${ }^{1}$ Ankara University, Graduate School of Social Sciences, Cebeci, Ankara, Turkey and ${ }^{2}$ Izmir Institute of Technology, Department of Molecular Biology \\ and Genetics, Urla, Izmir, Turkey
}

\begin{abstract}
Biotechnology, defined as the technological application that uses biological systems and living organisms, or their derivatives, to create or modify diverse products or processes, is widely used for healthcare, agricultural and environmental applications. The continuity in industrial applications of biotechnology enables the rise and development of the bioeconomy concept. Bioeconomy, including all applications of biotechnology, is defined as translation of knowledge received from life sciences into new, sustainable, environment friendly and competitive products. With the advanced research and eco-efficient processes in the scope of bioeconomy, more healthy and sustainable life is promised. Knowledge-based bioeconomy with its economic, social and environmental potential has already been brought to the research agendas of European Union (EU) countries. The aim of this study is to summarize the development of knowledge-based bioeconomy in EU countries and to evaluate Turkey's current situation compared to them. EU-funded biotechnology research projects under FP6 and FP7 and nationally-funded biotechnology projects under The Scientific and Technological Research Council of Turkey (TUBITAK) Academic Research Funding Program Directorate (ARDEB) and Technology and Innovation Funding Programs Directorate (TEYDEB) were examined. In the context of this study, the main research areas and subfields which have been funded, the budget spent and the number of projects funded since 2003 both nationally and EU-wide and the gaps and overlapping topics were analyzed. In consideration of the results, detailed suggestions for Turkey have been proposed. The research results are expected to be used as a roadmap for coordinating the stakeholders of bioeconomy and integrating Turkish Research Areas into European Research Areas.
\end{abstract}

Keywords

Bioeconomy, emerging trends in biotechnology, environmental biotechnology, framework programs, health biotechnology, industrial biotechnology, knowledge-based bioeconomy, primary production and agri-food biotechnology, TUBITAK, Turkey

\section{History}

Received 15 November 2012

Accepted 2 April 2013

Published online 1 July 2013

\section{Introduction}

Industrial politics is one of the central elements of development economics. In the 1980 s, it was perceived only as enabling industrialization to improve productivity, but today it is accepted as the establishment of a knowledge-based industry. Along with the increasing accumulation of knowledge in life sciences and biotechnology, the concept of bioeconomy entered swiftly into the agenda. Bioeconomy is perceived as the contribution of the knowledge acquired from the life sciences to economy in terms of new products and processes, and it commonly involves various economic sectors including health, food, agriculture, pharmaceuticals, chemistry and the environment. Increasing Research and Technology Development (RTD) work has significantly contributed to the conversion of the elements specifically in bioeconomy to innovative, sustainable, eco-friendly and competitive products. In the current situation, the concept

Address for correspondence: Dr. Yusuf Baran, Associate Professor, İzmir Institute of Technology, Department of Molecular Biology and Genetics, 35430, Urla, Izmir, Turkey. Tel: +90 232 7507315. Fax: +90 232 7507509. E-mail: yusufbaran@iyte.edu.tr of "Knowledge Based Bioeconomy" (KBBE) is now in the research agenda of many countries such as the European Union (EU), USA, Japan, India and Brazil.

Knowledge-based bioeconomy usually has three dimensions: (1) using advanced gene knowledge and complex cell processes to develop new products and processes, (2) supporting sustainable production using renewable biomass and efficient bioprocesses, (3) integrating biotechnology knowledge and applications across sectors (OECD, 2009). Preliminary literature research on the concept of knowledge based bioeconomy shows that there are various studies considering impacts on ecology and sustainability, rural development, knowledge transfer systems, corporate structures, economic analysis of innovation in bioeconomy, policies and research priorities, future foresights, and foresights for triggering and the development of bioeconomy.

With the review of previous studies, it becomes evident that the international comparison of technological advances on knowledge based bioeconomy has not been sufficiently studied. The deficiency in these studies is not only observed for Turkey but also for other countries (especially for developing countries). International comparison studies 
provide beneficial inputs for policy makers and contribute significantly to shaping future policies of the country. Projects funded under national and international civil research programs are important sources of data for comparison studies. It is possible to analyze the number, subjects and budgets of funded research, and draw various conclusions. Therefore, EU Framework Programs (FP), which has been implemented since 1984 and which is the main tool for funding research in the EU, is an important source of data in these studies. Basic objectives in the background of EU FPs are; to integrate the scattered research capacity in the EU, to focus on areas identified in line with various policies, to increase the dissemination of knowledge and to strengthen the competitiveness of the EU. RTD participants in Europe cooperate in thousands of projects financed by the European Commission and try to ensure technological development and solve problems. Currently, FP7 is being implemented covering the period between 2007 and 2013 and Turkey is participating in this Program as an associated country.

The objective of this article is to assess the progress of Turkey in bioeconomy through researching the development of Knowledge Based Bioeconomy in the EU. R\&D projects implemented in biotechnology in Turkey and the EU will be analyzed in this study. In the analysis, the subjects, numbers, budgets of the projects and prominent subject clusters among all the research activities will be identified. Thus, the priorities of Turkey and Europe in sub-research and technology areas in the scope of bioeconomy will be compared and various future strategies and policies will be suggested for Turkey. Moreover, suggestions and strategies as a "road map" will be produced in order to improve integration and cooperation with the EU and to increase the participation of research groups in Turkey in the 7th Framework Program (FP7) in this knowledge based bioeconomy.

\section{Concept and development of knowledge-based bioeconomy}

\section{Bioeconomy and knowledge-based bioeconomy}

Bioeconomy is defined by OECD (2006) as "the aggregate set of economic operations in a society that use the latent value incumbent in biological products and processes to capture new growth and welfare benefits for citizens and nations'. In this sense, biotechnology covers all the industries and economic sectors that produce, manage and use the resources. Bioeconomy guided by principles of sustainable development and environmental sustainability can only be discussed if biotechnology has a significant share of economic outputs. Biotechnology is usually classified in three main headings as health biotechnology, industrial biotechnology, and primary production and agri-food biotechnology (OECD, 2009).

Along with biotechnology based products used for therapeutic purposes such as biopharmaceuticals, preventive products such as vaccines and diagnostic products are in the scope of health biotechnology. Biotechnology is also frequently used as a process technology in pharmaceutical sector where the end product is a chemical. In the field of health biotechnology, it is foreseen that important technological advances will be witnessed especially in therapy with tissue engineering, cell and gene based therapies and nano-medicine (European Commission, 2007a).

Industrial biotechnology, on the other hand, is a developing field being used as an alternative to chemical processes and fossil fuels especially in environment and energy issues. It involves different fields, such as bioenergy, biorefineries, biofuel and biomass, industrial bioenzymes in energy sector, biomaterials such as biodegradable plastics in packaging sector, biocosmetic products in self-care sector and other different technological areas such as nanobiotechnology and biosensors being used in many fields.

Primary production and agri-food biotechnology is being used especially in fields such as rehabilitation, diagnosis and therapy, production of fine chemicals and enzymes. Biotechnology based diagnosis and veterinary products used mainly in vaccines have a role of controlling and monitoring in critically important areas such as animal diseases, zoonoses and food safety. In addition, it has significant importance in selection and improvement of the characteristics of biotechnological organisms. Genetically modified plants are the most important examples for this (European Commission, 2007a).

Some data about the contribution of biotechnology in the economy is listed below:

- It is between 350 billion USD and 1 trillion USD in the food industry and agriculture (Herper \& Kang, 2006).

- USA's pharmaceutical sales are 600 billion USD into the world market and 250 billion USD into the USA domestic market (Herper \& Kang, 2006).

- Agriculture in the EU consists 1.8\% of the gross national product and $5.9 \%$ of total employment (CIAA, 2009).

- Food industry in the EU consists $2 \%$ of the gross national product and $13.5 \%$ of total employment (CIAA, 2009).

The world population is expected to increase by approximately 2.3 billion in 2050 and this increase will require a $70 \%$ increase in the food production (FAO, 2009). Moreover, there will be a significant increase in demands for animal feed, fibres for clothing, and clean water and energy. To be able to meet this demand in a sustainable way, and since the land available for agriculture will be decreasing, higher productivity and efficiency will be needed. In order to overcome the negative effects of climate change, it is expected that KBBE and biological processes will improve and that the renewable materials obtained and biofuels produced from plants will become more widespread. In addition to these problems, in the future, it is expected that the need for sustainable development will increase due to increased consumption, lifestyles and eating habits will change. The need for healthier, safer and higher quality of food will increase as will the need for control and prevention for epidemics and zoonoses (OECD, 2009).

In the recent years, with the increase in the need for a sustainable supply of food, raw materials and fuel, KBBE started to stand out. Innovativeness is perceived as the most effective way to increase the quality of life, to ensure sustainable food production and to protect the environment while increasing productivity and competitiveness. Since the life sciences and biotechnology are important areas for having a healthier and more sustainable life, and for developing production processes that are more environment friendly, KBBE has made important contributions to economic 
development and global problems, and offers solutions for a more competitive and sustainable society (European Commission, 2010a).

\section{Knowledge-based bioeconomy in the European Union}

When the subjects in the scope of KBBE in EU policies are researched, it is observed that the issue has especially become more important after the Lisbon Summit in 2000 and has been included in both research and other policies. Within the scope of the European Research Area (ERA) established following the Lisbon Summit, it is aimed to increase the cooperation between centers of excellence, to integrate the scattered research activities in Europe, to increase the efficiency of equipment use, to enhance the mobility of researchers, and to integrate scientific communities (European Commission, 2000). To achieve these goals, first the 6th Framework Program (FP6) was realized between 2002 and 2006 and then the 7th Framework Program (FP7) started for the period between 2007 and 2013. KBBE was included in both programs as one of the priority areas.

One of the most visible studies of the European Commission discussing specifically KBBE and defining it as one of its priorities is the strategy document "Life sciences and biotechnology - A strategy for Europe" published in 2002 (European Commission, 2002a). This document includes various strategies on how Europe can attract human, industry and finance resources, how Europe can implement policies that react in a fast and effective way, how Europe can answer the global problems, and there are 30 actions identified in the document. The report, which is prepared under the headings of harvesting the potential, governing life sciences and biotechnology, responding the global challenges and implementation and coherence across sectors, actors and policies, defines in which areas biotechnology should be supported in the future, what should be done to apply the intellectual property rights effectively to trigger $\mathrm{R} \& \mathrm{D}$, and what longterm changes are needed in EU legislation (European Commission, 2002a).

The European Commission had an interim evaluation of the Life Sciences and Biotechnology Strategy in the year 2007, and strengthened the action plan through highlighting the need to promote some more areas. The updated action plan is more focused on KBBE compared to the first plan. Accordingly, in the new action plan, in life sciences, biotechnology and KBBE, main headings of promoting research and market development are: fostering competitiveness, knowledge transfer and innovation from science base to industry, encouraging social debates on benefits and risks, ensuring a sustainable contribution of modern biotechnology to agriculture and finally improving the implementation of legislation and its impact on competitiveness were established (European Commission, 2007a).

EU Framework programs, being the most important tool for implementation of these studies of policy determination in research and technology development, have become the mechanism where KBBE is most supported in the EU. $R \& D$ projects carried out with partners in order to develop, implement or research novel knowledge, products or technologies have been the most important part of FP6 and FP7 and were supported with a large budget (European Parliament, 2006).

In FP6, the subjects within the scope of KBBE are mainly supported in the areas of "Life Sciences, Genomics, and Biotechnology for Health" and "Food Quality and Safety". According to the data declared by the European Commission (2010a), the Food Quality and Safety area was supported by a budget corresponding to $4.2 \%$ of the total budget of FP6. A budget of over 750 million Euros was granted to 181 projects with 3034 participants.

In FP7, subjects within the scope of KBBE are supported in the areas of "Health" and "Food, Agriculture and Fisheries, and Biotechnology". In FP6 and FP7, the calls have been and are still managed through annual work programs. Priority areas were identified in these work programs, and project proposals were required to be pursuant to these priority areas. The changes that occurred in the basic priority resulted from the transition from FP6 to FP7 are given in Tables 1 and 2.

European Technology Platforms (ETP), have been in operation since 2003 with the aim of monitoring the research policies in Europe and reflecting the priorities of industry to research policies, have also had important contributions to KBBE research policies. ETPs assess the medium and longterm technological advances and the added value for society focusing on the obstacles for growth and contribute to the integration of research in Europe by increasing the intensity of the research. There are nine ETPs established in areas related to KBBE (CORDIS, 2012):

- ETP Plants for Future,

- ETP Food for Life,

- ETP Sustainable Chemistry,

Table 1. Main priority changes of food areas in FP6 and FP7 (European Commission, 2005; European Commission, 2010b).

FP6 food quality and safety - areas

Total budget (2002-2006): 753 million Euros

1. Total food chain

2. Epidemiology of food-related diseases and allergies

3. Impact of food on health

4. Traceability processes along the production chain

5 . Methods of analysis, detection and control

6. Safer and environmentally friendly production methods and technologies and healthier food stuffs

7. Impact of animal feed on human health

8. Environmental health risks
FP7 food, agriculture and fisheries and biotechnology - activities Total budget (2007-2013): 1.9 billion Euros

1. Sustainable production and management of biological resources

2. Fork to farm: Food, health and well being.

3. Life sciences, biotechnology and biochemistry for non-food products and processes. 
Table 2. Main priority changes of health area in FP6 and FP7 (European Commission, 2002b; European Commission, 2007b).

\begin{tabular}{ll}
\hline $\begin{array}{l}\text { FP6 health }- \text { areas } \\
\text { Total budget (2002-2006): 2.5 billion Euros }\end{array}$ & $\begin{array}{l}\text { FP7 health - activities } \\
\text { Total budget (2007-2013): 6.1 billion Euros }\end{array}$ \\
\hline $\begin{array}{ll}\text { 1. Advanced genomics and its applications for health } & \text { 1. Biotechnology, generic tools and medical technologies for human health } \\
\text { 2. Combating diseases } & \text { 2. Translating research for human health } \\
& \text { 3. Optimizing the delivery of health care to European citizens } \\
& \text { 4. Other actions across the health theme }\end{array}$ \\
\hline
\end{tabular}

- ETP Sustainable Farm Animal Breeding and Reproduction,

- ETP Forest-based Sector,

- Biofuels ETP,

- Agricultural Engineering ETP,

- Aquaculture Technology and Innovation, and

- Global Animal Health.

In addition, there are other networks regarding the research policies of $\mathrm{KBBE}$ and established and supported by the European Commission. The Food, Agriculture and Biotechnology Advisory Group gives feedback and presents suggestions to the European Commission on research. KBBE-Net is coordinated by the European Commission General Directorate for Research and it brings together the representatives of EU member states. This network coordinates the work for establishing and implementing research policies on related subjects. Network of KBBE National Contact Points provides support to research groups and industrial enterprises planning to apply for EU funds. The Standing Committee on Agricultural Research is managed by the European Commission and gives prospective research policy suggestions on issues regarding production in many sectors with a KBBE perspective (European Commission, 2007a).

\section{Knowledge-based bioeconomy in Turkey}

The first time biotechnology was included in national science and technology policies in Turkey was with the inclusion of biotechnology as one of the five priority areas in the "Turkish Science Policy" document approved in the second meeting of the Supreme Council for Science and Technology on February 3, 1993 (TUBITAK, 1993). In this document it was decided that priority will be given to biotechnological studies and that a biotechnology center will be established in Southeastern Anatolia Project (GAP) region.

Until the 2000s, the policies of science and technology determined in Turkey were not considered to be fully implemented. Therefore, in its meeting on December 13, 2000, Superior Council for Science and Technology decided to prepare the Turkish Science and Technology Strategy Document for the period between 2003 and 2023. Within the scope of the project entitled "Vision 2023: Science and Technology Strategies,' sub-projects of Technology Foresight Project, National Technology Inventory Project, Researcher Information System (ARBIS) and TUBITAK National Research Infrastructure Information System were implemented, and strategic technologies and priority R\&D areas for Turkey were identified. In this context, "Vision 2023 Biotechnology and Genetic Technologies Strategy Group Report', is considered to be the most comprehensive study on science and technology policies regarding biotechnology (TUBITAK, 2004).

The Biotechnology and Genetic Technologies Strategies document is focused on four main sectors. These are, in order, health, agriculture, animal husbandry and industrial biotechnology. Some of the objectives identified in the study are given below (TUBITAK, 2004):

- Identification of the genetic components of diseases and increasing their use in prevention, diagnosis and therapy.

- Competency in survey and design of pharmaceutical technologies.

- Developing new plant genotypes which are resistant to common stress factors and improved by various quality factors in herbal products with high added value.

- Developing molecular biology techniques in the diagnosis and control of plant diseases and pests.

- Dissemination of applications of diagnosis systems of GMOs and use of molecular methods in evaluation and monitoring of environmental impacts.

- Developing economically valuable animals with the use of biological and biotechnological methods in animal improvement.

- Developing molecular diagnosis, animal pharmaceuticals and vaccines based on biotechnology and gene technologies and putting them into use.

- Developing alternative energy sources.

- Developing environment friendly industrial production processes.

Following Vision 2023, in the 10th meeting of Superior Council for Science and Technology on September 8, 2004, the basic goals, principles and objectives of Turkey in science and technology were identified. These elements all together form The Turkish Science and Technology Strategy. In this strategy, the main objectives of Turkey in Science and Technology are identified as; increasing the demand for R\&D, increasing the number and quality of scientists, technical and vocational workers, and increasing the share of $R \& D$ spending in gross national product. After this date, the resources allocated to $R \& D$ reached the maximum amount in the history of The Turkish Republic. In the current situation, the subjects in biotechnology are supported through TUBITAK Support programs for Academic R\&D, Support programs for Industrial R\&D, and Support programs for Research Projects of Public Institutions. The amount of support provided for biotechnology projects in general under these programs are significantly increased.

\section{Data and research method}

R\&D projects supported within the scope of EU Framework programs between 2003 and 2010 in biotechnology and 
national R\&D projects supported by TUBITAK Department of Research Support programs (ARDEB) and The Department of Technology and Innovation Support programs (TEYDEB) in the same period in biotechnology are compared. The comparison is conducted with the perspective of their share in the total budget of support, the number of projects supported and the same and different headings of research in branches of biotechnology.

With this purpose, biotechnology research is primarily grouped under three main headings: Health Biotechnology, Industrial Biotechnology and Primary Production and Agrifood Biotechnology. Topics such as practices for human health, diagnosis, therapy, pharmagenomics for tailor-made therapy and medical tools are discussed under the heading of health biotechnology. Production processes of chemicals, plastics and enzymes, production of bioremediation, biosensors and biofuel, research on nanobiotechnology and synthetic biology, and marine and fresh water biotechnology topics are discussed under industrial biotechnology headings. Primary production includes all the natural resources such as forests, plants, livestock, fish and aquaculture and biotechnology is mainly used for improvement and production of plants and animals. In addition, topics such as genetically modified organisms, biotechnological analysis of risks in the food chain and development of new methods for facilitating research are also discussed under this last heading.

For the analysis of EU support, $103 \mathrm{R} \& \mathrm{D}$ projects supported the "Food Quality and Safety" thematic area and 471 R\&D projects supported the "Life Sciences, Genomics and Biotechnology for Health" thematic area from the 6th Framework Program implemented between 2003 and 2006, and 197 R\&D projects supported Food, Agriculture and Biotechnology Theme and $458 \mathrm{R} \& \mathrm{D}$ projects supported in Health Theme from the 7th Framework Program between 2007 and 2010 were used as a data set (CORDIS, 2010a, 2010b). The titles and abstracts of these projects had been analyzed and those related to biotechnology were identified. After that, relevant projects were placed under subheadings, the EU budget was allocated into headings, and the subjects that need further research were defined.

For the analysis at the country level for Turkey, biotechnology projects supported by ARDEB between 2003 and 2010 were acquired through a search with keywords "omic technologies, bioinformatics, genetics, genetic engineering, protein engineering, tissue culture, cell culture, bioprocess, enzyme engineering, synthetic biology, molecular biology, genome, physiology, microbiology, biochemistry, algae, plant genetics, animal genetics, bioeconomy, bioenergy, marine biotechnology, biorefinery, genetically modified organism (GMO), fermentation, enzyme, biodegradable, nanobiotechnology, bioremediation, biocatalyst, environment biotechnology, food biotechnology, and industrial biotechnology". Among the 575 projects identified from this search, those that were not deemed relevant according to their subject headings and abstracts were excluded, research and rapid support project types were addressed, and the total number of projects was reduced to 251 (TUBITAK, 2010a). On the other hand, for biotechnology projects supported by TEYDEB, 260 projects related to biotechnology were selected and analyzed among the projects supported by the Biotechnology,
Agriculture, Environment and Food Technologies Group (BIYOTEG) in the aforementioned period (TUBITAK, 2010b).

\section{Outcomes of the analyses}

In the initial four years of FP6 and FP7, the period between 2003 and 2006, the total support provided by the European Commission on Biotechnology was calculated as approximately 2 billion Euros, $61 \%$ of this budget was allocated to health biotechnology, 23\% was allocated to primary production and agri-food biotechnology, and $16 \%$ was allocated to industrial biotechnology (Figure 1).

According to the statistics obtained from the funded projects by TUBITAK, the budget allocated for these subtopics in Turkey is proportionally parallel to the EU with $61 \%$ of this budget allocated to health biotechnology, 22\% allocated to primary production and agri-food biotechnology, and $17 \%$ allocated to industrial biotechnology (Figure 2).

The trend analysis conducted for the EU and Turkey data has shown which sub-topics of biotechnology show an increase or a decrease trend. Since EU Framework programs are multi-annual programs planned for a certain period with their objectives and budget, this comparison was not conducted in terms of years, but in terms of the total period of the two programs. Accordingly, in the scope of FP6 and FP7, approximately $60 \%$ and the same amount of funding was allocated to health biotechnology. The point to remember is the fact that when moving to FP7 from FP6, the budget allocated to health biotechnology did not change despite an increase in the general budget and in the budget allocated to health research.

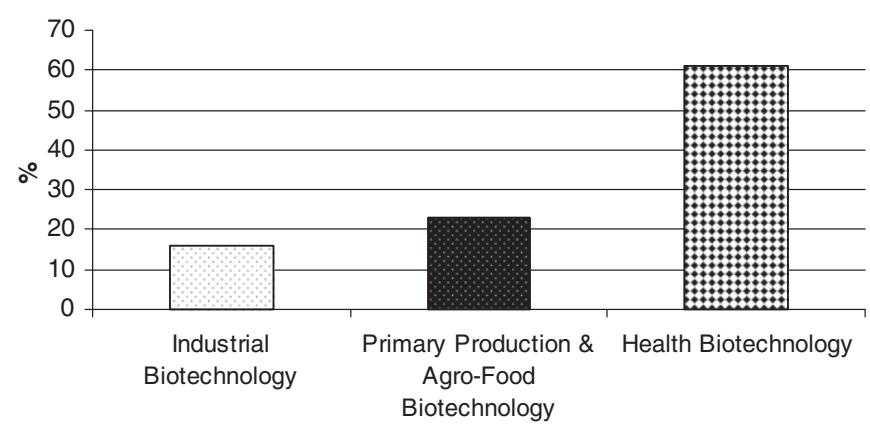

Figure 1. Share of sub-fields in biotechnology related R\&D projects funded by EC.

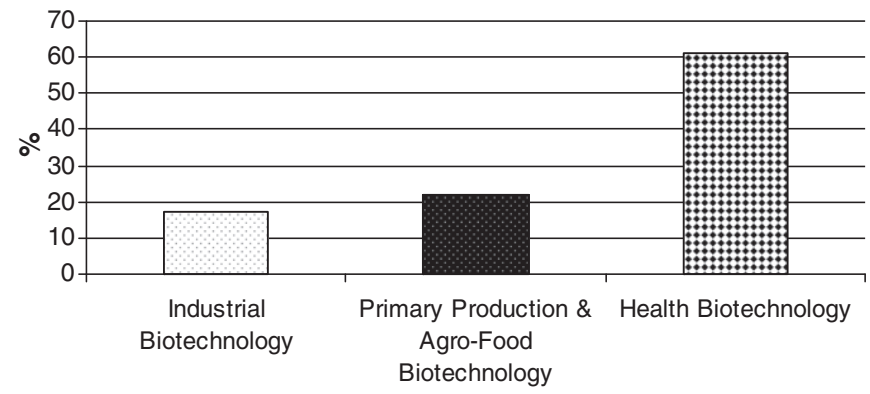

Figure 2. Share of sub-fields in biotechnology related R\&D projects funded by TUBITAK. 


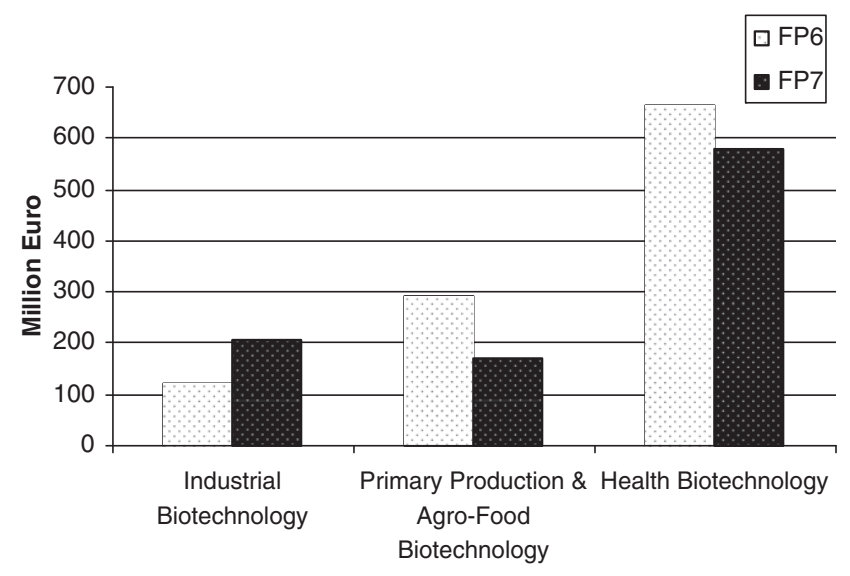

Figure 3. Share of sub-fields in total budget spent to biotechnology related R\&D projects (FP6 and FP7) $(\mathrm{M} €$ ).

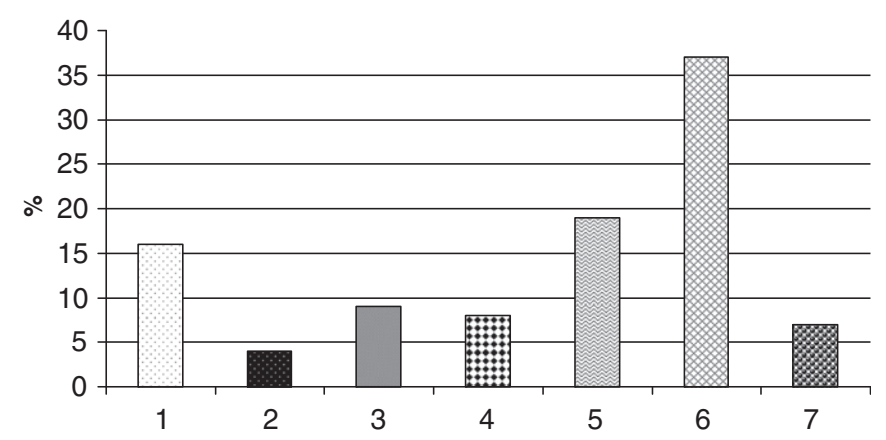

Figure 4. Distribution of project budgets supported by EC in Health Biotechnology (2003-2010). 1. Omics Technologies, 2. Biobanks and population genetics, 3. Model organisms, 4. Systems medicine, 5. Diagnostics and imaging tools and technologies, 6. New therapies and immunization strategies 7 . Alternative testing strategies.

Primary production and agri-food biotechnology was supported with a ratio of $27 \%$ in FP6, but this ratio decreased to $17.6 \%$ in FP7. This decrease is thought to be related to the acknowledgement of the key role of industrial biotechnology in reaching the KBBE objectives of $\mathrm{EU}$ and to the increase in the funding transferred to industrial biotechnology. Likewise, the name and scope of the area "Food Quality and Safety" in FP6 is modified to "Food, Agriculture and Fisheries, and Biotechnology" in FP7. Food quality and safety became a sub-topic supported in this area. In the same thematic area, projects proposed to all the sub-areas of biotechnology except health biotechnology started to be supported. Consequently, the ratio of support for industrial biotechnology was $11 \%$ in FP6 and increased to $21.7 \%$ in FP7 (Figure 3).

The funding allocated by the EU Commission to research projects in the sub-areas of health biotechnology between 2003 and 2010 and the topics are summarized below (Figure 4).

New therapies and immunization strategies area is the subtopic that received the largest share in health biotechnology with its support budget being over 450 million Euros. As a result of clinical research on this topic, it is intended to obtain more personalized, tolerable solutions, and it is aimed to develop technologies for organ transplantation and bioartificial organs. More than 50 projects considering diagnosis and imaging tools, and technologies aiming to develop the tools necessary for research, diagnosis and therapeutic guidance were supported. The European Commission has transferred nearly 200 million Euros of funding to omic technology research. By means of structural genomic studies, which are studies on DNA sequencing, faster and less costly identification of 3 dimensional structures of proteins has been achieved.

Approximately, 110 million Euros of funding was transferred to research projects on model organisms like mice, rats, zebra fish, plants, nematodes and bacteria. These projects played an important role in establishing a basis for knowledge related to diseases and health and in structuring the research environment in Europe. Moreover, they ensure the production of important and accessible data and/or animal sources that will accelerate biomedical research. The LUPA project with a budget of 12 million Euros, which was supported in 2008, aims to discover the molecular basis of complex disorders using dogs as model organisms. Of the two projects that were supported in 2010, 10.5 million Euros were transferred to a EURATRANS project researching the functional causes underlying cardiovascular, metabolic and behavioural disorders in humans using rat models, and 11.30 million Euros were transferred to the ZF-HEALTH project researching the genetic basis of brain development, behavioural and neurological disorders in zebra fish with the homologue of human genes related with diabetes, obesity, cancer and infectious diseases.

Between 2003 and 2010, the European Commission transferred approximately 100 million Euros to systems medicine and its applications. Research projects were supported on integrated testing strategies, cell based technologies, omic technologies, bioinformatics and computational biology, computational modelling, and forecast techniques. By this means, better, faster and cheaper methods of testing were developed.

However, in 2009, within the scope of the long term strategy determined by the European Commission General Directorate of Research Directorate of Health, it was aimed to abandon repeated systemic toxicity tests. It is foreseen that topics such as analysis of the safety of methods to replace animal tests, correct dosage modelling, establishment of toxicity studies database will be supported in the calls to be opened in the years to come.

Between 2003 and 2010, the funding allocated to topics of biobanks and population genetics was approximately 50 million Euros. Funded projects were pioneering the technique development studies for population genetics and studies researching the genetic tendency for diseases on large populations. In addition, funding support was granted for the development of protocols compatible with the collection, preservation and management of samples and genetic data of patients throughout Europe.

Funding transferred to the research projects in the subtopics of industrial biotechnology by the European Commission between 2003 and 2010 is summarized below (Figure 5).

Industrial biotechnology is the area that received the greatest share with a funding of approximately 90 million Euros. Improvement of biorefineries will decrease Europe's dependency on fossil fuels and these researches are focused 


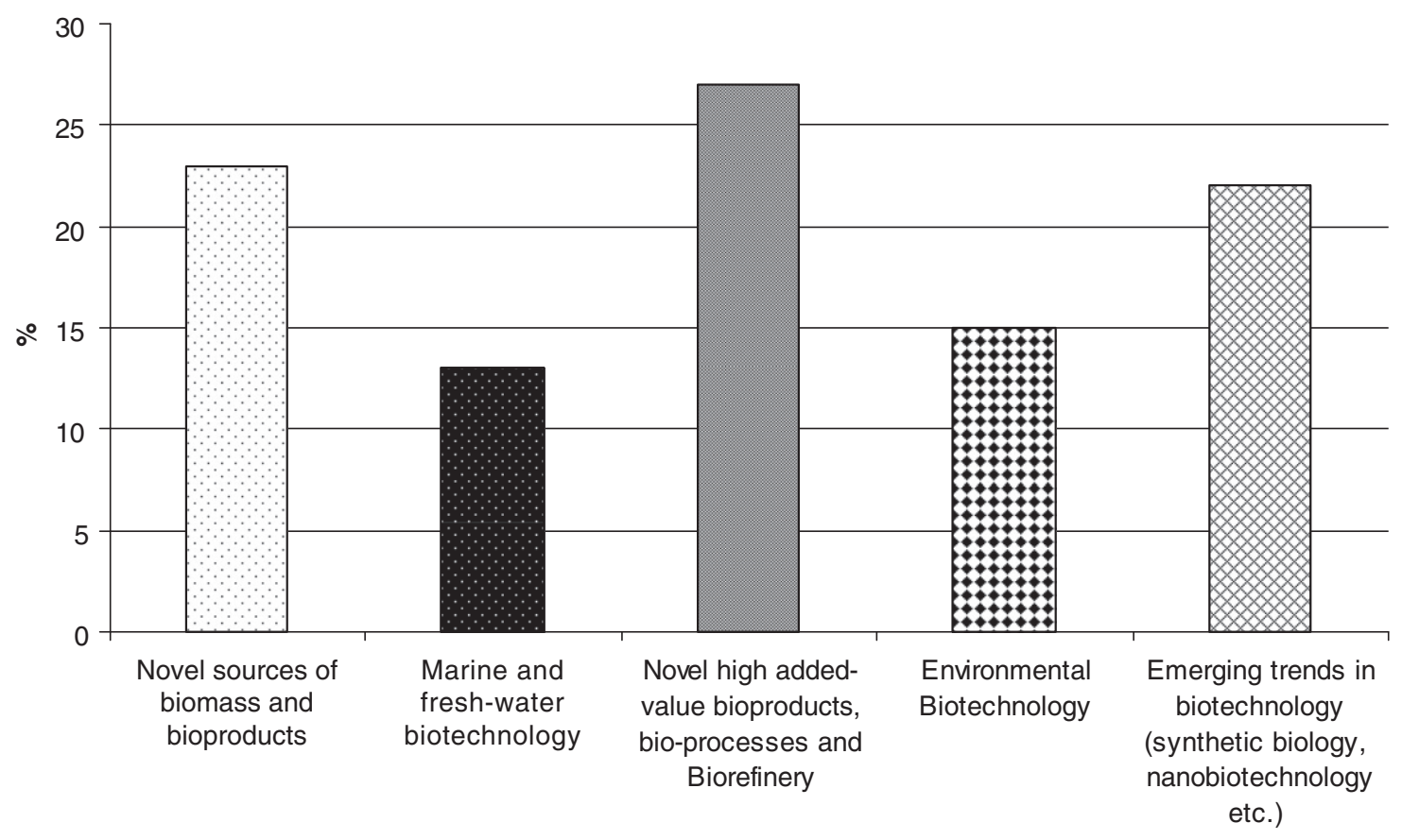

Figure 5. Distribution of project budgets supported by EC in industrial biotechnology (2003-2010).

on the improvement of lignocellulosic biorefineries for the production of biofuels and chemicals. In future funding calls, it is expected that research funding will be granted to biopolymer production, development of microbial high energy density fuels, and conversion of carbon dioxide into fuel and chemicals. Europe is the leader in industrial biotechnology, especially in fine chemicals and the enzyme market. The research activities during FP7 enabled the discovery and development of new enzymes to be used in sectors such as medicine, environment, food and chemicals. More research in the development of new and resistant microorganisms, and the optimization of bioprocesses, is expected to be funded in the future calls.

In the area of novel sources of biomass and bioproducts, which received approximately 75 million Euros of funding, it is observed that plant development work directed to obtaining bioproducts such as small natural molecules, natural polymers and oils for pharmaceutical use is accelerated. Moreover, support was given to bioenergy applications. Various energy plants such as hemp, sweet sorghum, and jatropha were developed, and the usability of biomass was analyzed. Research of plant compounds for agro-chemistry and cosmetics applications and discoveries of plan-based bioproducts are the subject of ongoing research. Another area that received equal funding is the emerging trends in biotechnology (nanobiotechnology, synthetic biology). Topics such as bionanotechnology, which is the production of new and biosimilar materials inspired by biology, and production of nanotools with special functions are expected to be supported in future funding calls as well.

Activities supported in environmental biotechnology mainly reflect the EU 2020 strategy and target smart and sustainable growth, aiming to transfer the know-how acquired from research projects to industrial products and processes, and by this means, to increase the competitiveness of European industry (European Commission, 2010b).
Even though research was carried out on basic microbial diversity and ecology used in bioremediation, the transferred budget and acquired know-how is limited.

In Europe, marine and fresh water biology is one of the areas with the most progress both in terms of the number of projects and budget. In the future funding calls, projects that will coordinate marine and maritime research and policies are expected to be supported.

Funding was transferred by the European Commission to research projects in the sub-areas of primary production and agri-food biotechnology between 2003 and 2010 and the topics are summarized below (Figure 6).

Biotechnology for safe and sustainable food is the area that received the largest amount of support with a funding of approximately 150 million Euros. More research on genetically modified microorganisms and animals is expected to be funded in the future calls of FP7. Also, it is foreseen that support will be given to social research directed to communication and social acceptance of GMO research. Nevertheless, new techniques that cause genomic changes and their biosafety in terms of health and environment will be important issues.

The main objective of enabling technologies areas is developing tools and technologies for basic plant/animal sciences, developing tools for genetics-genomics-system biology sciences, and the preservation and utilization of genetic resources in agriculture and forestry. The number of projects supported and the allocated budget of approximately 150 million Euros for this area in FP6 and FP7 reflects the importance attached to this area. On the other hand, because of its wide scope, there are many topics that need more research and that are expected to be supported in future calls of the FP. Some of these topics are: research on beneficial soil organisms and on microorganism-plant interrelations, research on biological/genetic foundation of processes that increase productivity, resource efficiency 
Figure 6. Distribution of project budgets supported by EC in primary production and agri-food biotechnology (2003-2010).
Figure 7. Annual distribution of research projects supported by TUBITAK (ARDEB and TEYDEB) in biotechnology according to sub-areas.
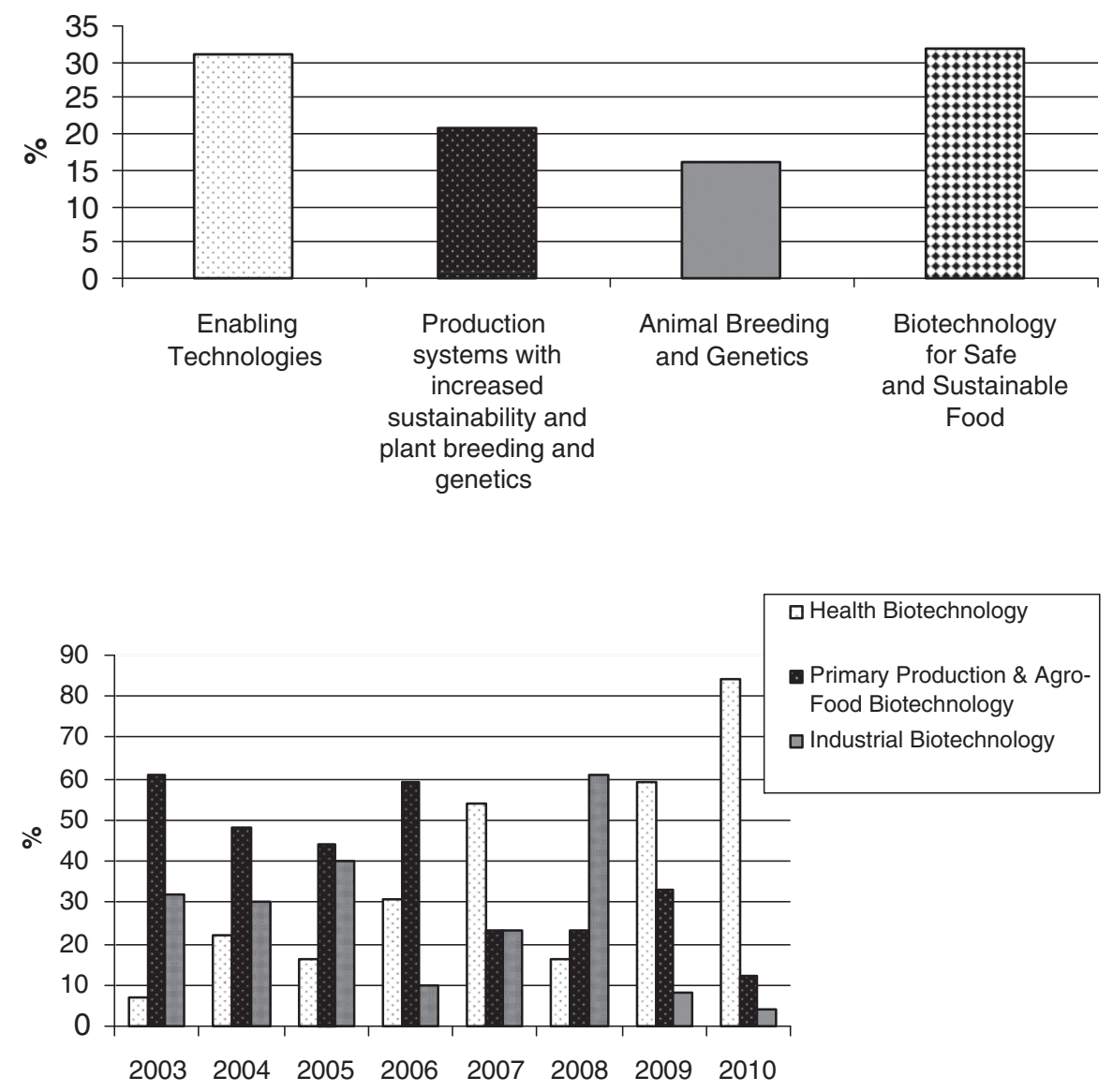

and tolerance to biotic/antibiotic stress, research on establishing pools for collecting genetic sources of crops of strategically importance, and research on biodiversity, epigenetics of farm animals, system biology and hostpathogen interactions.

Approximately 100 million Euros of funding was transferred to the production systems with increased sustainability and plant breeding and genetics between 2003 and 2010 and it is foreseen that in the future calls of FP7 more funding will be transferred to research on the scale of biological and resource management as well as criteria for soil use and carbon retention in agricultural soil and on the potential of biomass on this.

Projects on animal health, welfare and production related topics were supported in FP6 and especially between 2007 and 2010 in FP7. Breeding studies were also supported under the heading of enabling technologies. In addition, the effects of climate change on animal breeding were also researched. In the thematic area of health, topics intersecting in zoonotic diseases and antimicrobial resistance were supported. In the future calls, research on the use of omic technologies in animal breeding is expected to be supported.

The areas having trends of increase and decrease in biotechnology between 2003 and 2010 in Turkey are shown in Figure 7. Accordingly, health biotechnology has a trend for increase with exceptions in certain years, but primary production and agri-food biotechnology has a trend to decrease. On the other hand, industrial biotechnology, the only sub-area with a trend to increase in Europe, does not have any trends at all in Turkey. The reason for this is considered to be the fact that no specific policies have been developed regarding priority areas.

The amount of funding transferred to research projects in sub-areas of biotechnology by ARDEB and TEYDEB in the aforementioned period is shown in Figure 8. Since 2003, there has been a dramatic increase in the funds distributed by TUBITAK in this area. The amount of funding granted to biotechnology research by TUBITAK increased from $1,168,163 \mathrm{TL}$ in 2003 to $158,9242,426 \mathrm{TL}$ in 2010 , thus it was increased by $135 \%$.

In the projects supported in the scope of ARDEB in health biotechnology, $62.2 \%$ of the funding was transferred to omic technologies. However, instead of being large scale studies conducted in structural genomics such as DNA sequencing analysis, these studies could not go beyond being directed to understanding the mechanism of enzyme regulation and activity, to identifying the role of transcription factors in these mechanisms, and to establishing the impacts of external factors in molecular level, conducted with enzymatic, immunological and molecular biological methods. Apart from these, projects including biochemical research aiming to define the mechanism of enzymes and external materials are excluded from the analyses in this study since they do not have biotechnological value. Research in systems medicine, which is the area that received the second most support with $19.07 \%$, are limited to cell culture studies usually conducted in vitro directed to understanding the mechanism of diseases and to developing new therapy methods. The projects supported in the same area in EU analyze the relationships of genes, proteins, cells and organs with each other and with 
Figure 8. Annual budgets spent to biotechnology related $R \& D$ projects by TUBITAK (TL).

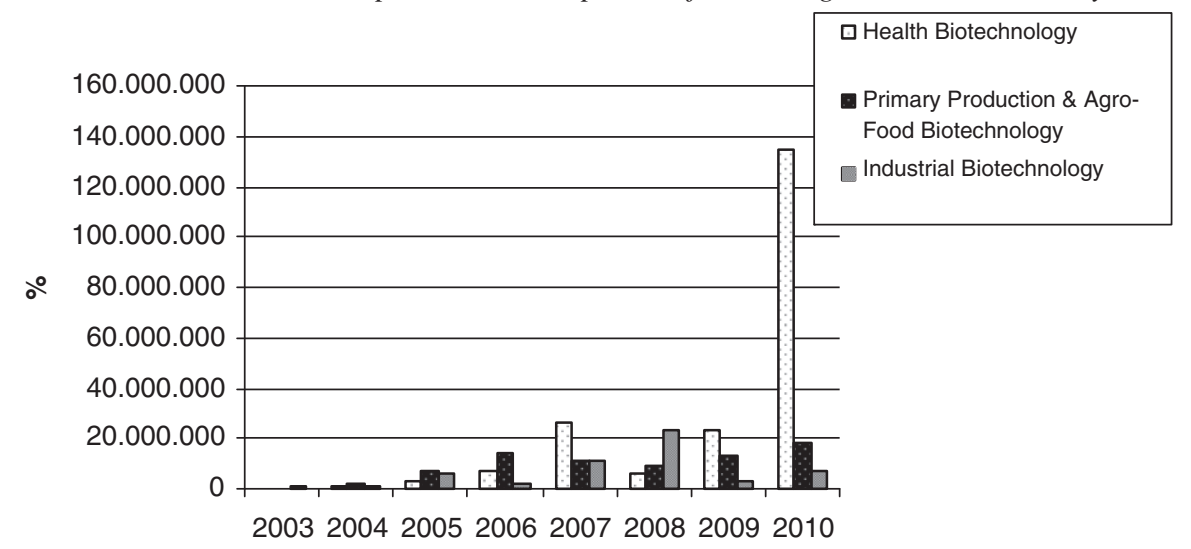

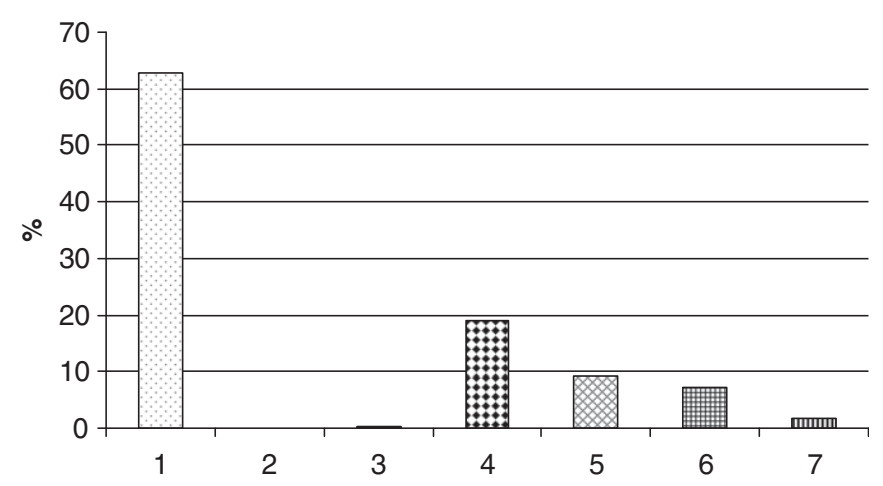

Figure 9. The distribution of the project budgets supported by ARDEB in Health Biotechnology according to sub-areas. 1. Omic Technologies, 2. Biobanks and Population Genetics, 3. Model Organisms, 4. Systems Medicine, 5. Diagnostics and Imaging Tools and Technologies, 6. New Therapies and Immunization Strategies, 7. Alternative Testing Strategies.

their environment in a wider scope. Diagnostics and imaging tools and technologies area, which is the most similar area in terms of research in Europe and Turkey, is the third most supported area. Studies on diagnosis and monitoring, and wide-scoped research projects that include tools and technologies such as biosensors were supported by ARDEB.

The projects supported in new therapies and immunization strategies, which are the fourth most supported area, are smaller in terms of scope, budget and number compared to the FP projects (Figure 9). All of the studies using model organisms conducted in Turkey consist of biochemical studies such as enzyme kinetic studies or genomic studies that aim to make genetic characterizations instead of understanding the mechanism of diseases and finding new methods of therapy, which was the case for the projects supported by the EU. Between 2003 and 2010, the area that is the least supported by ARDEB in health biotechnology is the biobanks and population genetics area. Studies that were supported by EU in this area such as collection and preservation of genetic data and development of new protocols did not receive any support in the scope of ARDEB in Turkey in the years mentioned. Nevertheless, there is only one project supported in population genetics which is a priority area in EU (TUBITAK, 2010a).

In the projects supported in the scope of TEYDEB in the sub-areas of heath biotechnology, $71 \%$ of the funds were

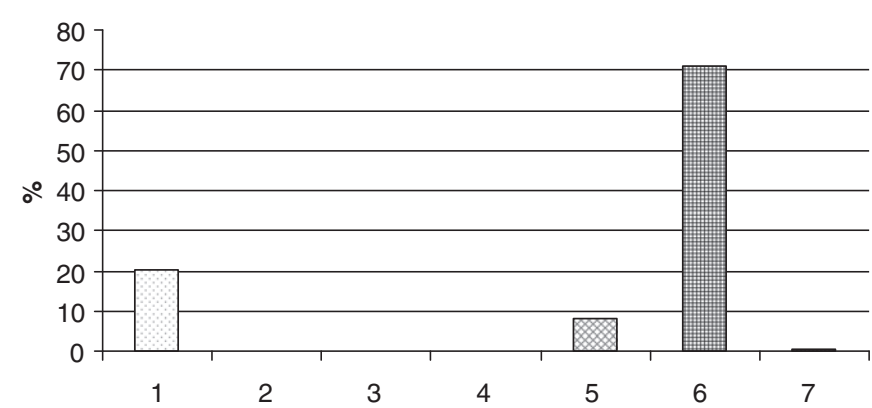

Figure 10. Distribution of project budgets supported by TEYDEB in Health Biotechnology according to sub-areas. 1. Omic Technologies, 2. Biobanks and Population Genetics, 3. Model Organisms, 4. Systems Medicine, 5. Diagnostics and Imaging Tools and Technologies, 6. New Therapies and Immunization Strategies, 7. Alternative Testing Strategies.

transferred to new therapies and immunization strategies (Figure 10). These projects were mainly implemented by large pharmaceutical companies and were on oncological product studies, new molecule research and synthesis studies, production of highly permeable gels, etc. However, it is thought that provoking these companies that were successful on the national level did neither participate as a partner in projects on new therapies and immunization strategies in FP7 nor in any health biotechnology project that Turkey was involved. In addition, even though it has not been included quantitatively in the analyses, it is striking that most of the funds granted in the scope of TEYDEB is transferred to the production of generic therapeutic pharmaceuticals. It is believed that encouraging research directed to finding new pharmaceutical molecules in plants would be more beneficial and have more added value and it would contribute to converting Turkey's potential to performance in this area, Omic technologies is the second most supported sub-area in the scope of TEYDEB despite the small number of projects supported because of the fact that they are projects with big budgets that are implemented by large pharmaceutical companies. In FP6, only one SME had participated in a project supported in omic technologies together with a university. In diagnostics and imaging tools and technologies which is the third most supported area, it is striking that the firms that received the largest amount of support are mostly SMEs. The total budget transferred to the 21 projects supported between 2003 and 


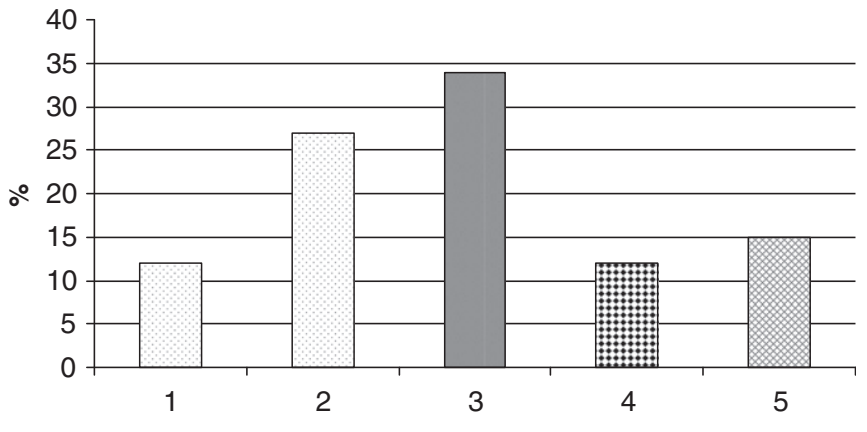

Figure 11. Distribution of project budgets supported by ARDEB in industrial biotechnology according to sub-areas. 1. Novel sources of biomass and bioproducts, 2. Marine and fresh-water biotechnology, 3 . Novel high added-value bioproducts, bio-processes and Biorefinery, 4. Environmental biotechnology, 5. Emerging trends in biotechnology.

2010 is approximately 16 million TL and this is promising considering the fact that the SMEs are the locomotive of the economy. While no projects were supported between the years mentioned in the scope of TEYDEB in biobanks and population genetics and model organisms, only one project was supported in systems medicine that was implemented by a large pharmaceutical company (The study on permeability of anti-Parkinson pharmaceutical combination in intestinal and blood-brain models). Only five projects, three in the scope of ARDEB and twi in the scope of TEYDEB, were funded in alternative testing strategies in Turkey (TUBITAK, 2010a; TUBITAK, 2010b).

In the projects supported in the scope of ARDEB in industrial biotechnology, 34\% of the funding was transferred to the sub-area of novel high added-value bioproducts, bioprocesses and biorefinery (Figure 11). Approximately 1.7 million TL was transferred to the 16 projects supported in this sub-area between 2003 and 2010, and subjects such as production of value added products like new enzymes, organic fertilizers, animal feed, and biofuels, obtaining enzymes from thermophilic bacteria, and enzyme kinetics and optimization.

The second most supported area is marine and fresh water biotechnology. However, Turkey's seas and fresh water resources are considered to be another resource in which Turkey has natural competitive edge. In a country surrounded on the three sides by water, marine resources are not sufficiently studied. Therefore, there is not a sufficient level of information on the processes to obtain products from these resources, and this subject is not included in any strategic studies in the political sense. On the other hand, the importance of these resources has entered into both the research agenda and the political agenda with FP7 in Europe. The studies directed to obtaining value added products like pharmaceuticals, feed and food, fuel, etc. have accelerated since 2007 (European Commission, 2010a). A university and 2 SMEs from Turkey are currently supported by the European Commission as partners of a project aiming to obtain biofuels from algae (CORDIS, 2010b). Mechanisms should be introduced to ensure the know-how acquired from these projects to return to Turkey (Figure 11).

In the projects supported by ARDEB on environmental biotechnology in Turkey, it is observed that mainly refining

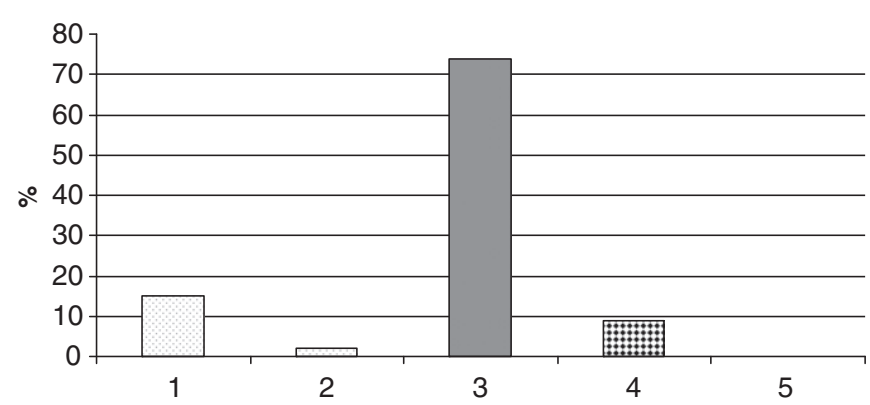

Figure 12. Distribution of project budgets supported by TEYDEB in industrial biotechnology according to sub-areas. 1. Novel sources of biomass and bioproducts, 2. Marine and fresh-water biotechnology, 3. Novel high added-value bioproducts, bio-processes and Biorefinery, 4. Environmental biotechnology, 5. Emerging trends in biotechnology.

textile waste waters were studied. In the area of novel sources of biomass and bioproducts that received an equal amount of support, research and technology development projects on production of food additives, chemicals, active ingredients of pharmaceuticals and antioxidants from plants were supported.

In the projects supported by TEYDEB on industrial biotechnology, the sub-area of novel high added-value bioproducts, bio-processes and biorefinery is again in first place with $74 \%$ of the funding (Figure 12). Approximately, 36.9 million TL funding was transferred to the 36 projects supported. Projects were mainly proposed on production of value added products such as new enzymes, organic fertilizers, animal feeds, and biofuels from waste, obtaining enzymes from thermophilic bacteria, enzyme kinetics and optimization. However, contrary to the ARDEB distribution, marine and fresh water biotechnology is on the last places in TEYDEB budget distribution and this shows the lack of interest of the industry to this area. Novel sources of biomass and bioproducts are in the second place with a share of $15 \%$ and the environmental biotechnology area in third place with a share of $9 \%$ are the areas in which SMEs show interest. Projects such as production of food additives, chemicals, active ingredients for pharmaceuticals and antioxidants from plants and residential/industrial waste refining with membrane bioreactors, and prevention of petroleum pollution with microbial remediation, respectively are the subjects proposed by the industry, especially by SMEs. Mechanisms should be introduced to increase the number of these projects.

In addition, incentives to accelerate the research and technology development studies on emerging trends in biotechnology will increase the cooperation between Turkey and Europe and ensure that Turkey is not left behind. There were no projects supported by TUBITAK TEYDEB between 2003 and 2010 in the emerging trends in biotechnology area and this area became the least supported area in industrial biotechnology in terms of funding transferred including ARDEB data. However, it is proposed to establish new mechanisms for urgently starting/advancing research on specific topics of emerging trends in biotechnology such as synthetic biology, bionanotechnologies and, metabolic engineering in Turkey.

In projects supported by ARDEB on Primary Production and Agri-Food Biotechnology, 58\% of the funding was transferred to production systems with increased 


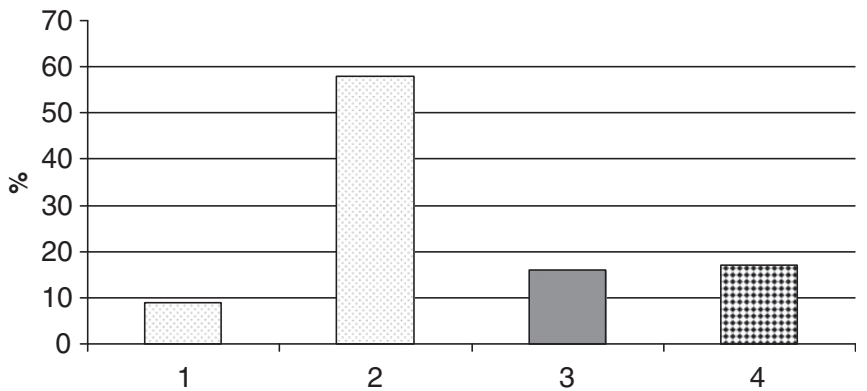

Figure 13. Distribution of project budgets supported by ARDEB in primary production and agri-food biotechnology according to sub-areas. 1. Enabling technologies, 2. Increased production technologies and plant breeding and genetics, 3. Animal production and genetics, 4. biotechnology for safe and sustainable food.

sustainability and plant breeding and genetics (Figure 13). This is the sub-area where the research conducted in Europe and the research projects supported in Turkey are most similar in terms of topics and budget, and the projects in this sub-area are mainly on abiotic stress tolerance/resistance of wheat, tissue culture studies for conservation of endemic plants, gene transfers, and production of some biomolecules in plants. Food biotechnology for the safe and sustainable food sub-area is in second place with $17 \%$ and approximately 1.9 million TL funding was transferred to 24 projects researching diverse topics from biodegradable packaging materials to functional foods, from genetically modified food and consumer perception to risk analyses in the food chain. The ratio of the projects funded in animal breeding and genetics is $16 \%$.

In the projects supported in the scope of TEYDEB in Primary Production and Agri-Food Biotechnology, similar to ARDEB, production systems with increased sustainability and plant breeding and genetics was in the lead and 53\% of the funding were transferred to this area (Figure 14). Supported projects are on production of highly efficient and high quality seeds, breeding studies of cotton-corn-sunflower-tomato, identification of genotypes to be used in breeding studies, development of plants resistant to abiotic stress and especially to drought. In biotechnology for safe and sustainable food sub-area which is in second place with $31 \%$, the supported projects were mainly on production of food enriched with biotechnological applications/functional food. Projects where vaccine development and animal breeding topics were supported had a share of $16 \%$.

In FP6 and FP7, primary production and agri-food biotechnology sub-area was the most successful area for Turkey with 17 funded projects and 4.5 million Euros fund returned to Turkey (CORDIS, 2010a, 2010b). Following this area, the projects on plant and animal breeding and on genetics, and the funding that returned to Turkey is approximately 1 million Euros for each area, making a total of 2 million Euros (CORDIS, 2010a, 2010b).

\section{Suggestions for Turkey}

Because of global warming, insufficient fossil fuel resources and the negative environmental impacts of fossil fuels, diseases that threaten human and animal health, problems of sustainability, quality and safety of agriculture and food sector, building knowledge-based bioeconomy has become

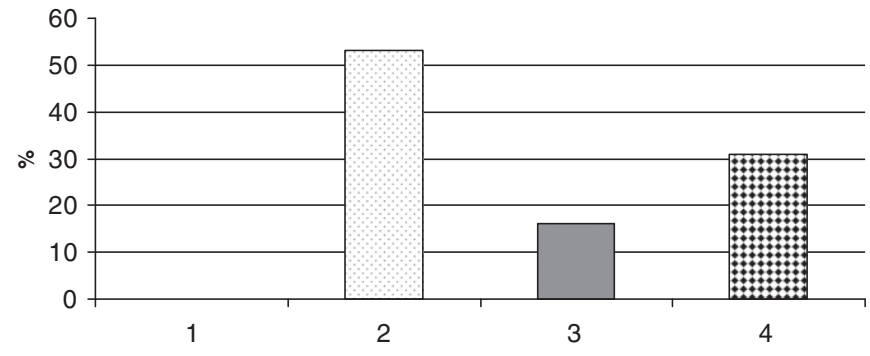

Figure 14. Distribution of project budgets supported by TEYDEB in primary production and agri-food biotechnology according to sub-areas. 1. Enabling technologies, 2. Increased production technologies and plant breeding and genetics, 3. Animal production and genetics, 4. Biotechnology for safe and sustainable food.

one of the priority strategies of many countries. Biotechnology and genetics have high potentials of developing alternative products and processes for the abovementioned problems and these technologies had a quick entry to production and service sectors with different applications in many areas. In the future, it is expected that biotechnology and genetic engineering will have a bigger share in various products and processes that will be reflected in human life and production sector, and that the outputs in economy will also increase. Therefore, the concept of a knowledge based bioeconomy will continue to be a constant priority for the agenda related to industrial and research policies.

In the policies and strategies implemented for KBBE, the specific conditions and potential of the country and the region must be taken into account. The most important elements for identifying successful policies and strategies are believed to be; current conditions, world order and value chains in the sector, raw materials in the country or region, human resources, institutional potential and correct identification of the future trends. Some of the policy suggestions developed for Turkey are given below:

\section{Capacity development}

- Encouraging research on biotechnology and genetic engineering. Developing a priority-driven research Program where cooperation between research institutions, universities and the private sector can be established, and implementing this program with specific funding calls.

- Identifying some key technologies in biotechnology and genetic engineering and developing mechanisms (specific funding programs, priority-driven research centers etc.) for implementing research on these specific technologies simultaneously and/or in cooperation with Europe and the world.

- Developing human resource capacities of public research institutes and research centers acting in KBBE and established in universities with the support provided by the State Planning Organization (SPO). Encouraging the use of national and international scholarships and programs to increase the number of researchers in these centers and institutes. Especially ensuring increased use of brain gain programs by these institutes.

- Preparing inventories and annual performances of existing biotechnology research centers. Structuring the 
resources of SPO in the light of this information in the years to come.

\section{Triggering the potential}

- Increased support to clustering activities for areas in the scope of KBBE. Selecting priority regions, realizing clustering projects.

- Supporting risk capital initiatives that will allow financing for the commercialization of innovation.

- Developing mechanisms that will support entrepreneurship in universities and especially in techno parks in areas within the scope of KBBE.

- Conducting large-scale pilot actions implemented by public-private partnerships in some priority areas of $\mathrm{KBBE}$ and dissemination of success stories to be realized.

\section{Governance and inter-institutional cooperation}

- Ensuring KBBE to be selected under Prime Minister's initiative with a decision of the Supreme Council of Science and Technology. Establishing a National Knowledge Based Bioeconomy Coordinating Council involving representatives of all of the relevant public institutions, non-governmental organizations, research institutions and the private sector to carry out work on KBBE.

- Encouraging the establishment of national technology platforms in related fields of $\mathrm{KBBE}$ for discussing technological priorities and for preparing research agendas for the private sector and making facilitative changes in the support mechanisms.

In conclusion, bioeconomy is an important opportunity for Turkey to achieve sustainable development and to have a globally competitive economy. For knowledge-based bioeconomy, first, national policies and strategies have to be developed considering the specific conditions of Turkey, its geographical location, and potential and strong and weak aspects of the country. Then, the opportunities must be used while taking the current global threats into account.

\section{Declaration of interest}

The authors report no conflicts of interest. The authors alone are responsible for the content and writing of this article.

\section{References}

CIAA (Confederation of the food and drink industries of the EU), Data \& trends of the European Food and Drink Industry, (2009).

CORDIS (2010a). Find a project. Available from: http://cordis.europa.eu/fp6/projects.htm [last accessed 1 Oct 2010].

CORDIS (2010b). Find a project. Available from: http://cordis. europa.eu/fp7/projects_en.html [last accessed 1 Oct 2010].

CORDIS (2012) “'Technology Platforms", http://cordis.europa.eu/tech nology-platforms/individual_en.html [last accessed 1 Feb 2012].

European Commission, Communication from the Commission to the Council, the European Parliament, the Economic and Social Committee and the Committee of the Regions - Towards a European Research Area, COM (2000) 6, Brussels, (2000).

European Commission, Decision No 1513/2002/EC of The European Parliament and of The Council, Brussels, (2002).

European Commission, Life sciences and Biotechnology - A strategy for Europe, COM (2002) 27, Brussels, (2002a).

European Commission, PRIORITY 1: Life Sciences, Genomics and Biotechnology for Health Work Programme, Brussels, (2002b).

European Commission, Thematic Priority 5: Food Quality and Safety 4th Thematic call Work Programme, Brussels, (2005).

European Commission, Midterm review of the Strategy on Life Sciences and Biotechnology, COM (2007) 175 final, Brussels, (2007a).

European Commission, Cooperation Theme 1 Health Work Programme 2007-2008, C (2007)2460, Brussels, (2007b).

European Commission, The Knowledge Based BioEconomy (KBBE) in Europe: Achievements and challenges full report, Belgian Presidency, Brussels, (2010a).

European Commission, Theme 2 - Food, Agriculture and Fisheries, and Biotechnology Work Programme 2011, Brussels, (2010b).

European Parliament, Decision No 1982/2006/EC of The European Parliament and of The Council, Brussels, (2006).

FAO (Food and Agriculture Organization) Report of the FAO Expert Meeting on how to Feed the World in 2050, Rome, 2009 June $24-26$.

Herper M, Kang P. (2006). The World s ten best-selling drugs, in Forbes.

OECD. (2006). The Bioeconomy to 2030: designing a policy agenda. Scoping paper. Paris: Organisation for Economic Cooperation and Development, Paris.

OECD (2009). The Bioeconomy to 2030, Designing a Policy Agenda, Main Findings and Policy Conclusions.

TUBITAK (1993). Bilim ve Teknoloji Yüksek Kurulu Türk Bilim ve Teknoloji Politikası 1993-2003, Ankara.

TUBITAK (2004). Biyoteknoloji ve Gen Teknolojileri Stratejisi - Vizyon 2023 Projesi Biyoteknoloji ve Gen Teknolojileri Strateji Grubu, Ankara.

TUBITAK (2010a). Academic Research Funding Program Directorate Projects Database.

TUBITAK (2010b). Technology and Innovation Funding Programmes Directorate Projects Database.

UNIDO (2009). Summary Report of UNIDO's Expert Group Meeting on Knowledge Based Bio Economy as Basis for Economic Development and Industrial Sustainability, Concepción, Chile. 